\title{
MARTín RIVAS: entre o Romance Histórico e o de Costumes
}

\author{
Alexandre Baquero Lima
}

\begin{abstract}
Resumo
Martin Rivas - Novela de Costumbres politico-sociales, de Alberto Blest Gana, foi publicado em 1862 e desde então tem sido reconhecido como uma obra realista de costumes, aos moldes dos romances de Balzac. O autor narra a exemplar ascensão de um "tipo social" que vem do interior para triunfar na alta sociedade aristocrática de Santiago. Inserida na tradição latino-americana da cidade letrada, esta obra busca presentear os leitores da época com esse herói romântico que paira acima de todos os outros personagens e que, no entanto, possui suas próprias contradições, particularmente derivadas das posições políticas de sua classe social. Nesse sentido, este artigo procura analisar tal personagem, Martín, em comparação com Ivanhoe, herói medíocre do Romance Histórico de Walter Scott, e com Rastignac, herói de Balzac em O Pai Goriot. De certa forma, a inadequação entre a forma realista do romance de costumes e as particularidades desse personagem romântico, longe de configurar um defeito da obra, explicita como sua estrutura interna assimila a especificidade histórica do conturbado momento político-social chileno.
\end{abstract}

Palavras-chave: Alberto Blest Gana; Literatura Chilena; Romance de costumes; Romance Histórico.

\section{Resumen}

Martín Rivas - Novela de Costumbres político-sociales, de Alberto Blest Gana, fue publicada en 1862 y, desde entonces, reconocida como una novela realista de costumbres "a la Balzac". El autor narra el ejemplar ascenso de un "tipo social" que viene del interior de Chile para triunfar en la alta sociedad aristocrática de Santiago. Este protagonista es un héroe romántico que resuelve todos los problemas de sus pares y que, sin embargo, posee sus propias contradicciones, particularmente derivadas de las posiciones políticas de su clase social. Así, este artículo pretende analizar el personaje de Martín, en comparación con Ivanhoe, el héroe mediocre del Romance Histórico de Walter Scott, y con Rastignac, protagonista de Balzac en Le Pére Goriot. Lo que planteamos es que la inadecuación entre la forma realista del romance de costumbres y las particularidades de este personaje romántico, lejos de configurar un defecto de la obra, explicita como su estructura interna asimila la especificidad histórica del conturbado momento sócio-político chileno.

Palabras clave: Alberto Blest Gana; Literatura Chilena; Novela de costumbres; Novela Histórica. 


\section{INTRODUÇÃO}

Martín Rivas - Novela de Costumbres politico-sociales, romance de Alberto Blest Gana publicado em 1862, obteve desde o começo um grande êxito de público e de crítica. Narrava a história de um burguês sem capital que vem do interior para triunfar na cidade grande através de seu próprio trabalho e guiado pela sua retidão moral. O livro tem início com uma dedicatória que já conduz o leitor a uma interpretação edificante da obra e que não podemos deixar de considerar: "su protagonista ofrece el tipo, digno de imitarse, de los que consagran un culto inalterable a las virtudes del corazón” (BLEST GANA, 2016, p.5, grifo meu). Essa manifestação do propósito autoral fornece uma chave de leitura para, ao menos, mais dois aspectos do romance: o narrador, onisciente e comentador, que será um porta-voz do autor para a crítica dos costumes da época; e o enredo, que vai demonstrar como os que se mantêm dentro do padrão de virtude serão premiados, por "su constancia y su trabajo".

O programa literário do autor pode ser conferido em seu discurso de posse na Faculdade de Humanidades da Universidade do Chile em 1861, um ano antes da publicação do livro. Naquele momento, Blest Gana comentava a situação embrionária da literatura chilena, afirmando a necessidade de que os poetas procurassem sua inspiração na coletividade e na história nacional, para que suas ideias pudessem prestar mais serviço à cultura do que ao simples entretenimento fugaz, e defendia o caminho da filosofia como base para a tarefa intelectual literária, se inserindo dentro da recente historiografia liberal romântica. Nesse sentido, o autor declarava sua preferência pelo romance:

la novela, por el contrario [de la poesía], tiene un especial encanto para toda clase de inteligencias, habla el lenguaje de todos, pinta cuadros que cada cual puede a su manera comprender y aplicar, y lleva la civilización hasta las clases menos cultas de la sociedad, por el atractivo de escenas de la vida ordinaria contadas en un lenguaje fácil y sencillo. Su popularidad, por consiguiente, puede ser inmensa, su utilidad incontestable (BLEST GANA, 1991, p.53, grifo meu).

A explicação de sua preferência pelo romance apresenta dois aspectos muito importantes para nossa leitura de Martín Rivas. Primeiro, essa "missão civilizatória" da literatura, espécie de Zeitgeist romântico da cidade letrada do século XIX, que abarca desde Sarmiento até José de Alencar, passando por Lastarria - que havia escrito o primeiro manifesto literário romântico do Chile em 1842. A principal diferença entre Blest Gana e eles reside no segundo aspecto dessa preferência: o emprego do modo realista do romance de costumes à la Balzac, por sua "popularidade e utilidade".

Uma vez que o subtítulo de Martín Rivas já promove a filiação da obra a essa tradição literária, a adição desse qualificativo "político-sociales" sugere algo a mais na relação entre ambos os termos e o que ela implica para os costumes a serem descritos. Se "sociais" tem a ver com a vida cotidiana das classes retratadas e com o enredo baseado em triângulos 
amorosos, o termo "político" determina que esses costumes retratados participem ou interfiram na vida política dos personagens e da sociedade e correspondam, dessa maneira, às ideologias da época. Essa correspondência pode ser verificada na própria dedicatória, como vimos, e nas amplas digressões do narrador sobre os costumes e política da época, bem como no cinismo com que o mesmo apresenta alguns de seus personagens. Ora, uma das linhas de força do livro reside, ao meu ver, nesse modo como as particularidades da época estão presentes na estrutura interna da obra.

\section{A República das Letras}

Já foi apontado pela crítica (CONCHA, 1997) que o distanciamento histórico entre o período em que ocorrem os episódios narrados (1850-1851) e o momento da publicação do livro (1862) é altamente significativo. Após duas décadas de governos conservadores e no início da terceira, o decênio de 1850 começava com uma revolta liberal - o motim de Urriola narrado no livro - contra o presidente Manuel Montt e terminaria com a eleição de José Joaquín Pérez, inaugurando a primeira de três décadas consecutivas de governos liberais. No entanto, a trajetória ascendente do liberalismo, da mesma forma que a de Martín, foi fruto de conciliações com o conservadorismo da época. De fato, um ano antes do mencionado motim de Urriola, José Victorino Lastarria publicava seu manifesto, Bases de la Reforma, em que propunha uma série de reformas para a lei de imprensa, para a lei eleitoral e para a guarda civil, entre muitas outras questões. Os críticos chilenos Istvan Jáksic e Sol Serrano destacam que, de forma implícita, o autor criticava a posição liberal da década de 1820 e, curiosamente, não pretendia alterar a Constituição Conservadora de 1833. Um de seus argumentos era o de que essa Constituição autoritária tinha sido importante para a manutenção da ordem na época e que, agora, "Las reformas son las únicas que impiden las revoluciones" (LASTARRIA, 1850, apud JAKSIC; SERRANO, 2010, p. 78). De certa forma, Lastarria pavimenta ideologicamente a acomodação liberal que irá criticar alguns anos depois.

Ao final da década de 1850, um dos motivos da desestabilização do governo conservador de Manuel Montt foi a aliança entre a ala mais moderada do liberalismo chileno com o grupo conservador ultramontano em torno à discussão constitucional sobre os direitos e deveres da igreja católica com o Estado. Esse conflito geraria a segunda revolta liberal da década, que, mesmo sufocada pelo governo, impediria Manuel Montt de fazer seu sucessor na presidência. O episódio ficou conhecido como a fusão liberal-conservadora de 1858, que Bernardo Subercaseaux definiu, para além da questão religiosa, como "una manifestación política de los vínculos entre la aristocracia terrateniente agroexportadora y sectores mineros y mercantilistas enriquecidos" (SUBERCASEAUX, 1997, p. 151), demonstrando que se tratava, sobretudo, de uma questão econômica. Se a divisão em dois grupos com visões distintas 
parecia distanciar suas aspirações políticas, o fato é que os privilégios da reduzida elite ilustrada, em face da população como um todo, desanuviavam as diferenças entre liberais e conservadores.

A razão fundamental de tais privilégios e a consequente supremacia dessa elite se explicam, segundo Angel Rama, pelo "paradoxo de que seus membros foram os únicos exercitantes da letra num meio desguarnecido justamente de letras, os donos da escritura numa sociedade analfabeta" (RAMA, 1983, p. 44). O caráter urbano e restrito desse grupo que controlava a comunicação e a ideologização do poder certamente contribuiu para essa aproximação, por acentuar suas afinidades e, também, suas diferenças em relação à população em geral. As tertúlias do "Círculo de Amigos de las Letras", associação literária que funcionou na casa de Lastarria com a intenção de promover a literatura nacional - num território neutro em assuntos de política e religião -, acabaram por distender as relações entre ambos os grupos (SUBERCASEAUX, 1997, p. 157), o que certamente contribuiu para a possibilidade de um concerto liberal-conservador. Blest Gana, que participou dessa elite ilustrada, primeiro como escritor e, posteriormente, também como diplomata, integrou e atualizou essa tradição latinoamericana da Cidade Letrada com sua obra, da qual propomos ler aqui o romance Martín Rivas.

\section{MARTín RIVAS}

Em seu ensaio sobre "O Pai Goriot de Balzac", Roberto Schwarz revela como, para além dos costumes, o dinheiro é o principal fio condutor da narrativa do autor francês, porque torna equivalentes todas as mercadorias à venda no romance, incluindo a memória e a beleza (SCHWARZ, 1963). Blest Gana também percebe essa mesma natureza arrasadora que amesquinha as relações sociais e, através de largos comentários do narrador, critica como "todo va cediendo su puesto a la riqueza" (BLEST GANA, 2016, p. 12). No entanto, as semelhanças param por aqui, porque Blest Gana "aperfeiçoa" o autor francês, conforme a postulação formulada por Doris Sommer, segundo a qual: “Talvez a maneira mais significativa [de aperfeiçoar] tenha sido o casamento do dinheiro com a moralidade, parceiros que parecem estar irreparavelmente separados por Balzac" (SOMMER, 1984, p. 258). E essa "correção" se manifestaria no personagem de Martín que, ao menos na intenção do autor, realiza esse "aperfeiçoamento" ao assumir os negócios de Don Dámaso e se casar com Leonor, sua filha e herdeira.

O primeiro aspecto relevante deste protagonista já foi indicado na dedicatória do livro: ele é um tipo social digno de ser imitado. Essa caracterização ecoará praticamente a todo momento no romance, pela força com que Martín destoa em relação aos demais personagens da história. Ele acompanha Rafael e Agustín ao picholeo ${ }^{1}$, mas não encontra diversão no meio da festa; repreende o seu futuro cunhado, Agustín Encina, por cortejar Adelaida, moça de 
extração humilde, e mesmo assim se esforça para resolver o falso casamento que lhes é impingido; ele dirige de forma inteligente os negócios de Don Dámaso Encina, o futuro sogro, por quem é reconhecido ao final do romance: "no miento si digo que debo a Martín mucha parte de las ganancias de este año" (BLEST GANA, 2016, p. 311). Dessa maneira, Martín é transformado numa espécie de herói romântico burguês, alter ego do autor, que compartilha dos seus ideais liberais e dos de seu amigo Manuel Antonio Matta, a quem o livro é dedicado.

O romance inicia-se com a chegada de Martín à casa de Don Dámaso. Todo o primeiro capítulo será dedicado à apresentação do protagonista e do seu anfitrião. A descrição de Martín é a de um jovem melancólico, com olhar apagado e pensativo, mas de estatura regular e formas bem proporcionadas:

El conjunto de su persona tenía cierto aire de distinción que contrastaba con la pobreza del traje, y hacía ver que aquel joven, estando vestido con elegancia, podía pasar por un buen mozo a los ojos de los que no hacen consistir únicamente la belleza física en lo rosado de la tez (...) (BLEST GANA, 2016, p. 08).

Este capítulo, assim, sumariza o jogo de contrastes com o qual o narrador nos apresenta o personagem em meio aos diálogos da cena inicial: a altivez de seu caráter esbarra na pobreza de seu traje, o que provoca o riso burlesco do criado. Da mesma forma, a inadequação de suas roupas provincianas ao ambiente citadino será tratada com escárnio pelo filho do burguês, Agustín, rapaz de modos pateticamente afrancesados. Esses contrastes derivam da origem de Martín, apresentada no capítulo seguinte em que somos informados da razão pela qual Don Dámaso deve alguns serviços ao seu pai. Com efeito, no passado, José Rivas possuía uma mina de prata no Norte e muitas dívidas com a casa de comércios de Valparaíso, para a qual o então jovem Dámaso trabalhava na época. Ao cobrar essas dívidas, e na posse do dote que recebera por seu casamento com a nada graciosa Doña Engracia, Dámaso tinha acordado, na ocasião, um empréstimo extremamente desvantajoso para o pai de Martín, que perdeu, assim, toda a sua mina pouco antes dela finalmente começar a render. Rebaixado então a administrador, José Rivas viu a fortuna de Don Dámaso crescer exponencialmente por conta dos juros cobrados de sua dívida.

A origem da fortuna do usureiro obriga a revisar, a partir dela, o pressuposto jogo de contrastes com o qual o protagonista foi descrito: Martín não é pobre, ele está pobre. Seu aspecto inicial contrasta com seu traje porque sua origem familiar, a sua essência natural é a de um burguês, o que significa que ele possui a potência de superar sua atual situação de vida. Tanto é assim que Leonor, a moça rica, justifica seu amor por ele alegando que "Martín, aunque pobre, tiene alma noble, elevada inteligencia; esto basta para justificarme"; e, sem resposta dos pais, continua: "es también de buena familia; no le falta, por consiguiente, más que ser rico" (BLEST GANA, 2016, p. 311). O casamento de ambos é o final feliz que coroa a 
ascensão do protagonista, mas não apenas pela riqueza alcançada e sim porque, acima de tudo, Martín se reencontra com sua essência social burguesa que estava camuflada pelos seus pobres trajes, no começo da história.

Muito diferente é o caso do oficial da Guarda Civil, Ricardo Castaños, que corteja Edelmira Molina, filha da modesta dona Bernarda, que promove as reuniões do picholeo. A única descrição que temos dele provem de uma fala do aristocrata, amigo de Martín, Rafael San Luís:

Edelmira ha soñado, tal vez, algo más poético en armonía con los héroes de folletín, porque desdeña los homenajes de este hijo menor de Marte que se desespera dentro de un uniforme como si se tratase de una perpetua postergación en su carrera (BLEST GANA, 2016, p. 56).

Tanto o protagonista quanto este capitão são jovens de poucos recursos econômicos, mas, enquanto Ricardo Castaños é apresentado como "um filho menor de Marte", Martín possui o potencial de se tornar o herói de folhetim de Edelmira. Dentro dessa concepção estamentária e rígida, fica claro por que o protagonista do romance não poderia ser um capitão de exército qualquer como Ricardo, ou por que Martín não poderia se casar com Edelmira, pertencente a uma família de substrato baixo, como a de medio pelo ${ }^{2}$. O que determina os casamentos no livro é a condição de classe de cada um, e não a situação, inclusive para Rafael San Luís. Sua história é marcada por um destino trágico porque ele teve um filho fora de sua classe, o que impede seu casamento com Matilde, amiga de Leonor e também de classe alta, união que tinha sido convenientemente arranjada pelo amor e pelo arrendamento da fazenda de tio dele.

A idealização romântica de Martín fica ainda mais evidente na comparação com o protagonista d'O Pai Goriot, Rastignac. Ambos os romances narram a trajetória de ascensão destes arrivistas, que logram adentrar nas classes aristocráticas de Santiago e de Paris, com especial atenção dos autores aos costumes das classes sociais retratadas. Não obstante, Balzac trata a ascensão de seu "herói” de forma completamente desiludida. A trajetória de Rastignac é a do abandono gradativo de seus escrúpulos pela vontade de penetrar nos altos salões de Paris. Em certo momento, o pérfido amigo Vautrin o aconselha a se casar com a jovem Victorine pela herança que receberá do pai, após a "repentina" morte do meio-irmão. Rastignac, escandalizado, rejeita a proposta em um princípio, mas, num momento de desespero, deixa o criminoso entender que está colocando seu plano em execução. Esse tipo de atitude é impensável para a moral estoica de Martín.

Se a ação final de Rastignac, de enterrar o pai Goriot, parece sugerir algo de redentor para a sua jornada, Balzac assim o faz apenas para zombar de mais essa ilusão no final do livro: o "Agora, somos nós" de Rastignac coroa a aprendizagem do protagonista que verte sua 
última lágrima de jovem sobre a colmeia buliçosa de Paris, agora determinado a lhe absorver o mel. Blest Gana, ao contrário, narra uma trajetória que ele julga isenta de pecados, pela ausência de comentários negativos sobre seu protagonista, ao tempo em que estes transbordam sobre os demais. Essa postura é idealizada porque redentora e livre da amarga e tão significativa desilusão do escritor francês.

Certamente, a história das ideias liberais no Chile nos propõe uma leitura romântica desta obra, caracterizada pela ideia de progresso e de construção nacional que Lastarria já havia proposto em 1842 e que Martín exemplifica e executa com seu final feliz. Dessa forma, ao passo que Balzac parece se preocupar mais com descrever Paris e seus vícios, Blest Gana intenciona normatizar a sociedade chilena. Essa idealização romântica e liberal de Martín, no entanto, esbarra em algumas contradições do personagem que, conforme aponta Laura Hosiasson, também se manifestam no narrador. A mais evidente é a participação do protagonista no mercado matrimonial de Santiago (HOSIASSON, 2004). A este respeito, nos ajuda a pensar Raymond Williams, quando afirma que as novas leis de herança em Londres, no século XIX, impulsionaram nas cidades a "temporada social": bailes, jantares e visitas que visavam o arranjo de casamentos entre os herdeiros das famílias e que o crítico inglês comparou a um mercado imobiliário (WILLIAMS, 1973).

Martín atua nesse mercado matrimonial como um agente de classe para frear as aspirações da família de medio pelo. Mais do que isso, o protagonista considera a hipótese do ricaço afrancesado Agustín se casar com a pobretona Adelaida como absurda: "Llamo locura, por ejemplo, que usted llegase a querer casarse con ella” (BLEST GANA, 2016, p. 99). Se essa atitude de Martín poderia se justificar pelo truque do falso casamento armado pelos irmãos Amador e Adelaida Castaños para também eles subirem na vida, não poderíamos dizer o mesmo sobre sua atuação na tentativa de fazer sumir a história do filho natural do amigo, Rafael San Luís. Nessa subtrama do romance, Martín chega ao ponto de subornar Amador, demonstrando que sua moral é indissociável de sua classe, pois não o impede de ajudar, com prazer, nas aspirações de seus pares. Aqui, com o propósito de narrar os costumes por um viés realista, o autor desvirtua as premissas liberais com que intencionava construir seu herói romântico, tornado-o medíocre em nome dos privilégios de sua classe social.

Nesse sentido, Martín é melhor comparado com Ivanhoe do que com Rastignac. No romance de Walter Scott, Ivanhoe não é herói por sua valentia ou força moral, e sim por servir ao autor como um elo entre as partes em conflito de sua época: é o filho deserdado de um nobre saxônio que cultiva amizade com Ricardo Coração de Leão, um rei normando. Ricardo e Cedric, o pai de Ivanhoe, representam as partes em disputa, assim como Robin Hood caracteriza a situação do povo em meio a essa grande crise da sociedade Inglesa. Já no romance de Blest Gana, Martín também serve de elo, ligando um resquício da aristocracia colonial conservadora ao primeiro liberalismo burguês, ainda heroico no Chile. É importante 
ressaltar aqui o desfecho desse protagonista. Como afirma Doris Sommer ironicamente, a institucionalização do romance nas salas de aula chilenas teve a ver com a celebração da chamada "vitória" liberal, "uma aliança com os conservadores que parece natural, quase inevitável no romance" (SOMMER, 1984, p. 260). Sem dúvida, o desfecho positivo da história de Martín sugere uma colocação em repouso do sistema de intrigas do romance, com o triunfo de sua condição burguesa e liberal sob a benção da figura moderada de Don Dámaso, comprovando que o sentido ideológico positivo, com o qual o autor quer destacar a figura do protagonista, paga tributo à ainda maior flexibilidade política de seu protetor.

\section{CONSIDERAÇÕES FINAIS}

Enquanto o Ivanhoe de Walter Scott pertence ao começo do turbulento período entre 1789 e 1848, Balzac escreve O Pai Goriot em seu final. A diferença, para Lukács, reside na virada ideológica que representou a Revolução de Julho de 1830 na França. Nesse momento, em que a burguesia se aliou à restauração contra a classe trabalhadora, o crítico húngaro enxergou um passo sem volta no ideário humanista burguês que orientaria a nova necessidade de figuração do presente como história, cujo grande representante foi Balzac (LUKÁCS, 1937). Ainda como aponta Lukács, o próprio romancista francês afirma no prefácio a Uma filha de Eva que Walter Scott havia esgotado as possibilidades de romances sobre o passado, sobre a luta de servos ou burgueses contra a nobreza, da nobreza contra a igreja, e que agora existiam infinitas possibilidades porque a igualdade na França permitia a cada indivíduo ter a fisionomia que lhe aprouvesse. Dessa forma, o crítico húngaro constrói uma linha de continuidade entre o romance histórico de Walter Scott e o romance de Balzac, baseada na historização dos problemas sociais para os quais ambos os autores foram mais sensíveis. Assim, o autor inglês figurara a história pregressa de seu tempo presente, enquanto Balzac narraria o presente como história, ilustrando as vicissitudes derivadas desse novo tempo capitaneado pelo dinheiro e sua capacidade de reduzir praticamente tudo a um preço.

Essa mesma sensibilidade é percebida por Blest Gana, que expõe com seus comentários algumas das futilidades causadas pela busca incessante do dinheiro e da imagem Amador Castaños e Agustín Encina são os melhores exemplos no romance -, mas o autor chileno ainda enxerga Balzac com olhos românticos. Uma vez que pretende civilizar as classes menos cultas da sociedade chilena, é fundamental perceber que sua opção pelo romance de costumes se deve também a uma "preocupación de índole esencialmente pragmática y extra literaria” (HOSIASSON, 2016, p. 14) que faz o personagem de Martín atravessar o livro incólume aos vícios e fraquezas da época retratada. Longe de configurar um erro de construção, a inadequação do modo realista de Balzac é com relação ao propósito romântico do autor, mas isso não acarreta a perda da lógica interna da obra, que apenas ganha mais 
camadas de sentido porque incorpora a especificidade histórica da época na estrutura do romance, particularizando em seu protagonista todas essas contradições, inclusive a do próprio narrador.

A mescla de gêneros de que resulta o romance de Blest Gana acaba, portanto, por ilustrar uma concepção nada romântica desse liberalismo chileno que se tornou conservador ao longo do século XIX, pois se fundava nas prerrogativas de uma classe que, conforme Gargarella (2005), resistiu em adotar a igualdade social de fato. 
1. Reunião festiva popular do século XIX chileno à base de bailes e bebidas. O autor as caracteriza por tratar-se de momentos nos quais "se ven adulteradas con la presunción las costumbres populares y hasta cierto punto en caricatura las de la primera jerarquía social, que oculta sus ridiculeces bajo el oropel de la riqueza y de las buenas maneras." (BLEST GANA, 2016, p. 62).

2. Jaime Concha define o medio pelo como um intervalo social existente no século XIX não coincidente com a nossa moderna classe média, cuja classificação é de ordem mais ideológicacultural que econômica (CONCHA, 1997, p. 62). No romance, também há uma longa definição desta classe. 
ARAYA, G. "Introducción". In: BLEST GANA, Alberto. Martin Rivas. Madrid: Ediciones Cátedra, 1998. pp. 13-50.

BALZAC, H. O Pai Goriot. São Paulo: Penguim, 2015.

BLEST GANA, A. Martin Rivas. Santiago de Chile: Zig-zag, 2016.

"Literatura Chilena: Algunas consideraciones sobre ella". In: KLAHN, Norma; CORRAL, Wilfredo. Los novelistas como críticos. México D.F.: Tierra Firme, Fce, 1991. pp. 46-58.

CONCHA, J. "Prólogo". In: BLEST GANA, Alberto. Martín Rivas. Caracas: Biblioteca Ayacucho, 1977. pp. 9-39.

GARGARELLA, R. "Le cycle tragique du libéralisme latino-américain (1810-1860)". In: Amérique Latine Histoire et Mémoire. Paris: Les Cahiers ALHIM, nov. 2005. Disponível em: $<$ http://alhim.revues.org/842>.

HOSIASSON, L. J. "Contradicciones de un narrador: Martín Rivas". In: Hispanismo 2002. São Paulo: Associação Editorial Humanitas; Associação Brasileira de Hispanistas, v.3, jan. 2004, pp.240-245.

"Una lectura del discurso de Blest Gana". 2016. Disponível em: $<$ https://disciplinas.stoa.usp.br/mod/resourc e/view.php?id=978725 $>$. Acesso em: 19 set. 2016.

JAKSIC, I.; SERRANO, S. "El Gobierno y las libertades". In: Estudios Públicos, Santiago de Chile: Centro de Estudios Públicos, n. 118, jan. 2010, p.69-105.

LARRAÍN, Sergio Fernández. Epistolario: Alberto Blest Gana 1856-1903. Santiago de
Chile: Editorial Universitaria, 1991.

LUKÁCS, G. "A forma clássica do romance histórico". In: O Romance Histórico. São Paulo: Boitempo, 2011. pp. 33-113.

RAMA, A. A Cidade das Letras. São Paulo: Boitempo, 2015.

SCHWARZ, R. "Dinheiro, Memória, Beleza". In: A Sereia e o Desconfiado. Rio de Janeiro: Paz e Terra, 1981. pp. 167-187.

SCOTT, W. Ivanhoé. São Paulo: Editora Abril, 1973.

SOMMER, D. "Algo para Celebrar: Núpcias nacionais no Chile e no México". In: Ficções de Fundação. Belo Horizonte: Editora Ufmg, 2004. pp. 253-283.

SUBERCASEAUX, B. Historia de las ideas y de la cultura en Chile. Santiago de Chile: Editorial Universitaria, 1997.

WILLIAMS, R. "Ciudad y campo". In: El campo y la ciudad. Buenos Aires: Paidós, 2001. pp. $75-84$. 